\title{
LA FÁBULA MITOLÓGICA EN ESPAÑA: VALORACIÓN Y PERSPECTIVAS ${ }^{1}$
}

\author{
VicENTE CRISTÓBAl LÓPEZ \\ Universidad Complutense de Madrid
}

Lo que expondré en las páginas que siguen es una visión del género poético hispano de la fábula mitológica ${ }^{2}$ desde los ojos de un filólogo clásico que tiene especial interés en la pervivencia y tradición de la literatura antigua. Serán consideraciones brotadas sólo de esta perspectiva y de este contexto. De modo que probablemente se me escapen ciertos otros datos y hechos que tienen su razón de ser en la sincronía, y cuyo estudio pertenece de lleno a los hispanistas.

1 Recibido: 30-XI-2009 Aceptado: 18-II-2010

2 Naturalmente, partiendo del panorama trazado por J. M. de Cossío en su clásica y valiosísima obra Fábulas mitológicas en España, Madrid, Espasa-Calpe, 1952 (ahora reeditada en dos volúmenes: Madrid, Istmo, 1998). 


\section{La FÁbUla mitológica ROMANCE, FRUTO TARDío DEL ALEJANDRINISMO POÉTico}

La mitología clásica ha tenido muchos cauces en la literatura española (historiografía medieval, lírica culta de toda época, teatro moderno y contemporáneo, prosa erudita, novela...), pero la fábula mitológica ha sido el más caudaloso sin lugar a dudas.

La fábula mitológica es un subgénero épico, de marcada distancia con la epopeya -obvio es- ${ }^{3}$. En realidad, se trata de una prolongación del "epilio" grecolatino ${ }^{4}$. Tanto la epopeya como la fábula mitológica son narración poética; pero frente a la desmedida extensión de la epopeya, la fábula mitológica es de más cortas dimensiones; y frente a los asuntos de interés comunitario o nacional propios de la epopeya, la fábula mitológica -como su nombre indica- saca sus temas del mito y la leyenda clásica, con especial incidencia no en las grandes empresas bélicas o viajeras, sino en episodios

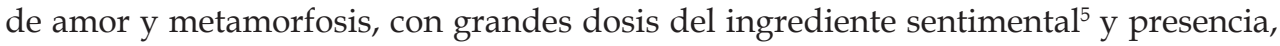
mayor que en la epopeya, de personajes femeninos. Podemos decir también que, mientras que a la epopeya la caracteriza, habitualmente, el compromiso nacionalista y comunitario, puesto que sus argumentos se enraízan en la historia patria o en las creencias e ideales de la comunidad, la fábula mitológica, en cambio, se nos aparece como género notoriamente descomprometido, que busca y se afana por la expresión artística en sí misma o ars gratia artis. Ahí vemos de nuevo, pues, reencarnada la antigua oposición alejandrina entre el "gran libro", que puede ser un gran mal por la amplitud de sus dimensiones (méga biblíon, méga kakón), y el libro pequeño, más adecuado, por el contrario, para su afinada revisión y limamiento estilístico: la oposición, en suma, entre la gran epopeya en muchos libros al modo homérico y el corto relato épico propugnado por alejandrinos y neotéricos.

El nexo que vincula al antiguo epilio alejandrino-neotérico con la moderna fábula mitológica es una obra romana concreta: las Metamorfosis de Ovidio, en su doble calidad de receptora y aglutinadora, por una parte, de argumentos de epilios alejandrinos perdidos y fuente habitual, por otra, de argumentos para fábulas mitológicas, que así se disgregan de su anterior común recipiente. Nótese lo peculiar de este proceso del que Ovidio en su obra es a la vez sujeto agente y paciente: hay un doble y sucesivo movimiento de sincretismo y disgregación, mediante el cual lo plural alejandrino se

3 Una caracterización breve del género, vinculándolo a la tradición antigua y al epilio alejandrino-neotérico, ya ofrecí en mi estudio sobre "Las Metamorfosis de Ovidio en la literatura española", Cuadernos de Literatura griega y latina, I (1997) 109-153 (en especial, pp. 135-140).

4 Sobre el epilio en la literatura latina, véase A. Perutelli, La narrazione commentata. Studi sull'epillio latino, Pisa 1979.

5 Supongo que es este mayor énfasis en lo sentimental lo que empuja a Cossío a considerar a la fábula mitológica más cerca de la lírica que de la epopeya (op. cit., I, p. 20). 
convierte en el acervo común ovidiano, de donde, a su vez, con la proliferación de la fábula mitológica, lo uno retorna a su originaria pluralidad alejandrina, ahora ya renacentista y barroca.

Y remontándonos un poco más en los orígenes del género, podemos preguntarnos cuáles fueron las razones artísticas que movieron a Ovidio para emprender su magna síntesis en quince libros de más de doscientos argumentos legendarios. A ello habría que responder apuntando a su intento de aunar y combinar lo homérico con lo alejandrino, según lo había intentado (y conseguido) Virgilio en la Eneida, pero de otra manera. Pues Virgilio había reducido la dimensión de la epopeya homérica hasta situarse en un poema que tenía la mitad de extensión de la Ilíada y la Odisea; había concedido también cierta autonomía a algunos episodios como el de Niso y Euríalo, el de Hércules y Caco, el de la niñez de Camila, en la línea del alejandrinismo cultivador de la épica menor, a la vez que había prodigado el ingrediente sentimental (en el episodio de Dido, pero no sólo) contra el modelo homérico y en obediencia a la corriente moderna, ya instaurada en la literatura romana desde antes de Catulo. Ovidio, en cambio, había renunciado a la estructura propia de la gran epopeya, en cuanto al hecho de que ésta se caracterizaba sobre todo por un héroe que centralizaba la acción y que la hacía avanzar hasta un punto determinado; en las Metamorfosis ovidianas no hay unidad argumental propiamente dicha: su obra épica es un conjunto plural de argumentos, una colección de epilios ensamblados en un todo narrativo y unificados por un ingrediente compartido: la transformación o metamorfosis; otro ingrediente que forma parte de muchos de los relatos comprendidos en la obra -si no de todos- es el tema amoroso; y Ovidio con esa acumulación de materiales había conseguido dar a su obra unas dimensiones (quince libros) que, como las de la Eneida, se situaban a medio camino entre las del epilio alejandrino-neotérico y las de la epopeya homérica; y con su alianza de temas bélicos, aventureros y centrados en un héroe, propios de la gran epopeya, y de temas eróticos, conflictos sentimentales y protagonismos femeninos, propios del epilio, había logrado, de manera singular, una mezcla de las dos tradiciones épicas, la que venía de Homero y la que arrancaba de Calímaco y continuaba en Roma con los poetae noui.

Este es el verdadero y remoto origen de la fábula mitológica hispana, género que se prolonga desde el Renacimiento al Neoclasicismo, y que no tiene apenas débitos con 
la tradición medieval hispana ${ }^{6}$. Sin embargo, el hecho de que el modelo narrativo y la fuente mayoritaria de argumentos sea el compendio de Ovidio no impide que se acuda también a otras fuentes mitográficas de la Antigüedad como el epilio tardío de Museo sobre Hero y Leandro (así Boscán), el relato legendario sobre Orfeo y Eurídice inserto en el libro IV de las Geórgicas de Virgilio (así también Boscán, que lo aprovecha para ampliar el argumento de su fábula sobre Hero y Leandro; así también Jáuregui, que lo aprovecha para su Orfeo) o el cuento de Cupido y Psique, narrado por primera vez en la prosa florida del novelista Apuleyo (así Gutierre de Cetina, aunque con mediación italiana, según Escobar Borrego ha demostrado7). Pero aún en esos casos, por lo general, el modelo narrativo sigue siendo el ovidiano de las Metamorfosis.

\section{TeRminOlogía: El CONCEPTO DE FÁBUla.}

"Fábula mitológica" es la etiqueta consagrada para denominar a este género poético, según consta sobre todo en la obra de Cossío. Y esta denominación tiene raíces antiguas.

La palabra fabula tenía en latín una notable polisemia ${ }^{8}$ : significaba, en primer lugar, 'conversación', 'charla', 'habladuría', 'rumor'(speciatim -precisa el Thesaurusrumores uulgi et maleuolorum sermo: "más en particular, rumores del vulgo y charla de los malévolos"); en segundo lugar, 'narración', 'relato', tanto en un sentido amplio y general, como en un sentido más restringido y particular, con la connotación, ya, de ligereza y falsedad; en tercer lugar vienen todas las acepciones de la palabra que se aplican no a la oralidad -como hasta ahora hemos estado viendo-, sino a la escritura, y

6 El capítulo que Cossío dedica en su monumental obra a los "Antecedentes medievales" (op. cit., I, pp. 26-53) estudia sobre todo muestras de la presencia material de los mitos ovidianos en nuestras letras (en algún pasaje del Libro de Alexandre, en muchos relatos insertos en la General Estoria, y en alusiones y ejemplificaciones de la poesía cancioneril y en la de Santillana y Mena). Lo más próximo que encuentra a la fábula mitológica, lo que podrían ser en cierto modo precedentes formales del género (por su presunto carácter híbrido de épica y lírica) son, en su opinión (pp. 47-53), los relatos versificados que se insertan en la Troyana polimétrica o el Llanto de Pentesilea, poema anónimo que ha sido atribuido al Marqués de Santillana. Pero es obvio que los rasgos comunes que pueda haber entre esas muestras y el Hero y Leandro de Boscán, y demás fábulas renacentistas, son pura coincidencia, sin que haya ninguna línea de continuidad genérica; y además la temática troyana de aquellos poemas es por lo general rechazada o, al menos, poco habitual en la fábula mitológica, sin duda por su consideración de materia histórica y no "fabulosa". En el ámbito de habla catalana podrían ponerse también como parcial antecedente del género, si no fuera por su carácter prosístico, los relatos mitográficos, fundados en Ovidio por lo general, de Joan Roís de Corella, relevante escritor del siglo XV. Un importante estudio de su obra ofrece Josep Lluís Martos, Fonts i seqüència cronològica de les proses mitològiques de Joan Roís de Corella, Alacant, Universitat d'Alacant, 2001.

7 F. J. Escobar Borrego, "Una fuente italiana desconocida para un poema de Gutierre de Cetina: la Historia de Psique traducida", Archivo Hispalense 253 (2000) 73-80, trabajo recogido y reelaborado ahora en su libro El mito de Psique y Cupido en la poesía española del siglo XVI, Sevilla, Universidad de Sevilla, 2002, pp. 47-76.

8 Cf. Thesaurus Linguae Latinae, VI, 1913, Leipzig (sub uoce), cols. 24-34. 
entre esas acepciones, además de otras como 'novela', ‘apólogo'(y ésta es la acepción más extendida hoy en castellano de "fábula", como bien se sabe) y `argumento de obra teatral' u 'obra teatral', está la que ahora nos interesa: 'mito'y 'leyenda', esto es: narración que pertenece a la mitología ${ }^{9}$ y que a menudo aparece como increíble, dudosa y enfrentada a la verdad de los hechos, a la visión realista.

En efecto, con el título de Fábulas (Fabulae) conocemos una de las obras de Higino, la que es compilación mitográfica de época insegura (pero en cualquier caso no anterior a época augústea, probablemente posterior al año $55 \mathrm{~d}$. C. y no datable después del 207 d. C. ${ }^{10}$ ), aunque no sabemos a ciencia cierta si ese título lo ostentaba el manuscrito en que su primer editor Micyllus se basó (Basilea 1535), códice en escritura beneventana del siglo IX ó X del que únicamente nos han llegado fragmentos, o por el contrario fue invención del citado editor (esta hipótesis alternativa se apoyaría en el hecho de que el propio autor, Higino, en el Poeticon astronomicon, otra obra suya, se refiere a las Fábulas con la denominación de "Genealogías", precedente así, por cierto, para el título del conocido tratado mitográfico de Boccaccio).

En cualquier caso, y como bien da cuenta de ello un libro de P. Demats ${ }^{11}$, el término cuenta con una larga historia en su aplicación a los relatos de la mitología, sobre todo en medios culturales cristianos de la Antigüedad tardía, y en dicho término subsiste siempre una noción claramente peyorativa (relato falso o inventado), que es concomitante también a las otras acepciones vistas del vocablo y tenía precedentes en el latín de época republicana.

San Agustín, por ejemplo (Soliloquios II 11, 19), hace decir a uno de los contertulios de su obra: Siquidem est fabula compositum ad utilitatem delectationemue mendacium ${ }^{12}$; y el escoliasta Servio (Schol. ad Aen. I 235), que muy a menudo opone fabula a ueritas, apunta la siguiente distinción entre fabula e historia: Et sciendum est inter fabulam et argumentum, hoc est historiam, hoc interesse, quod fabula est dicta res contra naturam, siue facta siue non facta, ut de Pasiphae, historia quicquid secundum naturam dicitur, siue factum siue non factum, ut de Phaedra ${ }^{13}$, donde, como es patente, et término sigue llevando carga

9 Para una definición científica de `mitología’y de `mito', mejor -a mi juicio- que ninguna otra, cf. A. Ruiz de Elvira, Mitología Clásica, Madrid 1975, pp. 7-8.

10 Véase una somera explicación de esta problemática en la introducción de S. Rubio a su traducción de la obra al castellano: Higino. Fábulas, Madrid, Ediciones Clásicas, 1997, pp. 4-6. Significativamente una edición anterior de la obra en Madrid, ed. Coloquio, 1987, aparecía con el título Fábulas: Mitología Clásica, con una glosa subtituladora que precisaba esa acepción antigua y extendida del término. Tengo noticia de que una nueva traducción al castellano aparecerá en breve en la prestigiosa colección Biblioteca Clásica de Gredos.

11 Fabula. Trois études de mythographie antique et médiévale, Genève 1973, pp. 5-37.

12 "Pues la fábula es una mentira elaborada para sacar de ella alguna utilidad o deleite".

13 "Y conviene saber que entre "fábula" y "argumento", esto es, "historia", esta es la diferencia: que 
negativa, en una línea que ya venía de la Retórica a Herennio (I 8, 13), que sentenciaba: Fabula est quae neque ueras neque ueri similes continet res, ut hae quae in tragoediis traditae sunt. Historia est res gesta... ${ }^{14}$; que venía también desde Cicerón, quien, por ejemplo, en su discurso Pro Milone (XVI 42) asociaba el sustantivo fabula a todo un cortejo de adjetivos depreciativos (fabulam falsam, fictam, leuem ${ }^{15}$ ), y en su tratado De officiis (III 26) oponía dicho concepto al de "cosa sucedida": Sed dimittamus et fabulas et externa; ad rem factam nostraque ueniamus ${ }^{16}$; y que de venía antes, ya desde Terencio, en cuyas comedias (Andria 224 y 553; Heaut. 336; y Phorm. 492 y 946) se significaba con la expresión Fabulae! algo así como: '(necias) habladurías', 'tonterías (a las que no hay que dar crédito)'. De modo que esta palabra ya en la Antigüedad aparecía connotada frecuentemente de manera negativa y, en cualquier caso, referida a acontecimientos de dudosa credibilidad.

En suma, el término trae vinculado a sí ese punto de vista y esa actitud de desconfianza hacia la materia de la poesía y hacia la poesía misma, que eran connaturales no sólo a la mentalidad cristiana antigua y medieval, sino a una buena parte de la mentalidad romana, tan pragmática por idiosincrasia, e, incluso antes, a la mentalidad de buena parte de la filosofía griega, especialmente la de Platón, con sus conocidos recelos frente a los poetas, porque encerraban -decía- mentiras en sus versos y eso no podía ser bueno para la formación de los ciudadanos. Que esa connotación negativa del vocablo haya prácticamente desaparecido del uso hispánico de los propios poetas a partir del siglo XVI es un indicio de la nueva mentalidad renacentista, que admira la poesía y la mitología como espejo y cauce de actitudes humanas, como fuente de belleza y entretenimiento.

En cuanto al término "epilio", usado recientemente y de forma constante por Ponce Cárdenas para referirse al género de la fábula mitológica ${ }^{17}$, es un calco del vocablo griego epyllion, que no tenía en la antigüedad clásica ningún sentido técnico ni servía para llamar al género épico cultivado por alejandrinos y neotéricos; fue sólo

\footnotetext{
"fábula" se dice de una cosa contra la naturaleza, tanto si ha sucedido como si no ha sucedido, como se cuenta de Pasífae, e "historia" se dice de todo aquello que ocurre según la naturaleza, tanto si ha sucedido como si no ha sucedido, como se cuenta de Fedra".

14 "Fábula" es una narración que contiene asuntos ni verdaderos ni verosímiles, como las que nos han sido transmitidas en las tragedias. "Historia" es un hecho sucedido".

15 "Fábula falsa, inventada, frívola".

16 "Pero dejemos de lado las fábulas y lo que viene de fuera; lleguémonos al hecho sucedido y a nuestras cosas".

17 Cito sólo dos títulos suyos en los que ya se muestra su uso: J. Ponce Cárdenas, “La poesía de Miguel Colodrero de Villalobos: Consideraciones en torno al epilio y los motivos del retiro en la naturaleza", en AA. VV., Góngora hoy, VI (coord. y ed. J. Roses), Córdoba 2004, pp. 145-198; y “Sobre el epilio burlesco: Aspectos léxicos y estrategias discursivas del erotismo en siete poetas barrocos", en I. Lacarra Lanz (ed.), Asimetrías genéricas: "Ojos hay que de lagañas enamoran": Literatura y género, Bilbao 2007, pp. 195-239.
} 
la filología historicista del siglo XIX la que -por analogía con el tecnicismo eidyllion, 'pequeño cuadro' o ‘pequeña escena'- adaptó el término, con el significado ya técnico de 'pequeño poema épico,' para referirse a producciones mítico-narrativas como la Hécale de Calímaco, la Europa de Mosco o el poema 64 de Catulo ${ }^{18}$. Este término frente a la denominación "fábula mitológica" tiene para algunos la desventaja de ir contra la tradición, tradición de llamar "fábulas" a los relatos míticos que viene también de la antigüedad latina, como hemos mostrado, a la que se atienen con frecuencia los propios poetas españoles en sus títulos y que nos viene consagrada por el estudio pionero de Cossío. Pero tiene la indudable ventaja, aparte de ser más escueto, de marcar la equivalencia con el género antiguo, así como la pertenencia de las obras al género épico y denotar su carácter menor frente a la epopeya; y de unificar la terminología técnica de la Filología Clásica y de la Hispánica.

\section{BREVE historia DEL GÉNERO EN EsPAÑA}

En la trayectoria seguida por la fábula mitológica en España podemos distinguir tres períodos, renacentista, barroco y neoclásico, que se identifican con los tres siglos XVI, XVII y XVIII, siendo el XVII su época de plenitud y mayor florecimiento: trayectoria bien estudiada por Cossío.

Hay un período inicial, un tiempo de los orígenes y de los poetas pioneros en el género. Entonces fueron escritas las fábulas ovidianas de Castillejo (sobre Acteón, Píramo y Tisbe, y Polifemo), que oscilan entre la traducción apegada al modelo y la recreación del mismo, con injerencia en alguna de ellas de aplicaciones morales, de rancio sabor medieval. Es el tiempo de la fábula, larguísima, de Boscán, en la que, partiendo del relato de Museo y de la versión italiana de Bernardo Tasso sobre la misma materia, inserta el autor en este tronco relatos subordinados como el de Orfeo y Eurídice, tomado de las Geórgicas; y es digno de tener en cuenta esa deuda con Italia a la hora de construir las primeras muestras del género. Modelo italiano, interpuesto al latino de Apuleyo, había también en la Historia de Psique traducida, compuesta por Gutierre de Cetina: dicho modelo lo será una anónima Fábula de Psique, escrita hacia 1530 y que acompaña a un ciclo de grabados sobre el argumento apuleyano de Benedetto Vernio y Agostino Veneziano ${ }^{19}$. Y modelo italiano tiene, de igual manera, en este primer período renacentista la Fábula de Adonis, Hipómenes y Atalanta de Hurtado de Mendoza, asentada en Ovidio tanto como en Parabosco; esta pieza nos pone, mejor que otras muestras, frente a otro rasgo del género: la posibilidad de injertar una fábula en otra,

18 Para la historia de este término aplicado a la literatura antigua, véase el capítulo incial del libro de A. Perutelli, op. cit., pp. 13-31.

19 Cf. el citado estudio de F. J. Escobar Borrego, “Una fuente italiana desconocida...” 
en lo cual se discierne bien clara la tradición antigua, pues muchas de las narraciones ovidianas (como la propia de Atalanta, subordinada a la de Adonis) son dependientes de otras que le sirven de marco, y antes de Ovidio, el epilio 64 de Catulo ofrece igual estructura de enmarcamiento: un relato mítico -el de Ariadna y Teseo-injerto en otro, el de las bodas de Tetis y Peleo. En fin, a este primer período pertenecen también las fábulas de autores como Gregorio Silvestre, Hernando de Acuña, Lomas Cantoral y Barahona de Soto, para las que a veces sirven de mediadoras con respecto al texto de Ovidio las traducciones italianas de Dolce y Anguillara. Cossío estudia también junto a estas muestras otros textos que, en mi opinión, no entran de lleno en los límites del género, aunque le sean vecinos: incluye, en efecto, la tradición romancística de tema mitológico, anónima o con autoría (por ejemplo, los romances de Juan de la Cueva), tradición que, en esos momentos, pertenece a un ámbito semipopular y semiculto, con raíces anteriores e independientes, creo, a las de la fábula mitológica (se incluyen, en cambio, ya en parámetros completamente cultos y dentro del género de la fábula mitológica los romances mítico-burlescos que se escriben a partir del XVII); tampoco, creo, se deben encerrar en el campo de este género el excurso ejemplar dependiente de un marco lírico, como es el caso del exemplum desarrollado sobre Anaxárete en la Canción V de Garcilaso, o el del mismo argumento injertado en una epístola de amor de Hurtado de Mendoza ${ }^{20}$.

Hay, en segundo lugar, un período de plenitud y florecimiento del género que coincide a grandes rasgos con el siglo XVII y con la novedad estilística traída por el cultismo barroco ${ }^{21}$. Góngora es, con su Fábula de Polifemo, el modelo de un género que, aún siendo narrativo, se complace en la pintura, descripción y glosa pormenorizada de personajes, paisajes y situaciones, deteniendo y frenando así el avance de la acción con una singular morosidad. El lenguaje se llena de metáforas, perífrasis y complicaciones formales, en las que se implica la propia mitología -cuyo uso no sólo atañe así a la inuentio, sino también a la elocutio (perífrasis, metonimias, metáforas, símiles, antonomasias, etc.)- y toda clase de latinismos, que distancian el discurso de todo público falto de instrucción. En este proceso evolutivo del género, el sesgo burlesco y desmitificador se incorpora en un cierto momento al relato mítico, lo que implica una parcial concesión al gusto popular; el tema se asocia entonces muy frecuentemente a la forma romancística y a una expresión no tan elevada (romances-fábula sobre

$20 \mathrm{Cf}$. mis comentarios al respecto en Mujer y piedra. El mito de Anaxárete en la literatura española, Huelva 2002, pp. 33-58.

21 Cf. mi trabajo "Mitología clásica en la literatura española: consideraciones generales y bibliografía", Cuadernos de Filología Clásica. Estudios Latinos 18 (2000), p. 38. Entre los estudios recientes sobre los poetas cultos que escribieron epilios, pueden recordarse los trabajos de J. Ponce Cárdenas sobre el baenense M. Colodrero: "La descriptio puellae en las fábulas mitológicas de Miguel Colodrero de Villalobos", Angélica, 9 (1999), pp. 77-88 y "La mentira pura de Baco y Erígone: breve nota a un poema burlesco", en AA. VV., Tiempo de burlas. En torno a la literatura burlesca del Siglo de Oro, Madrid, Verbum, 2001, pp. 145-160. 
Hero y Leandro de Góngora); pero otras veces ese rasgo se vincula y contamina con el estilo oscuro y metafórico, de modo que surgen piezas de una doble cara, docta y popular al mismo tiempo, que son, por así decirlo, doblemente barrocas por esa su simultánea distorsión formal y temática (tal es la Tisbe del propio Góngora)22. En la adopción de esta particular mirada frente a los mitos no fue, sin embargo, Góngora el autor pionero de nuestras letras, aunque sí fue él el que escribió versiones paródicoburlescas de mitos completos; pues tal actitud y tono constaba ya salpicadamente en la obra de algunos poetas andaluces de la segunda mitad del XVI como Hurtado de Mendoza, Baltasar de Alcázar, Francisco de Pacheco, Barahona de Soto y Juan de la Cueva $^{23}$. Para explicar genéticamente esta modalidad fabuladora del antiguo mito sin duda puede pensarse, por una parte, que tal punto de vista, bufo y humillante, frente a unos prestigiosos relatos es un modo de abrirse camino, en medio de esa materia fundamentalmente idealizadora, esa tendencia realista que tan fuertes raíces parece tener en nuestras letras; mas, por otra parte, ese tratamiento mítico es también habitual en la sátira antigua, tanto en la versificada que tiene a Lucilio, Horacio y Juvenal por autores modélicos, como en la prosística que representa Luciano de Samósata, escritor tan querido e imitado de los erasmistas, y no es, en consecuencia, descartable una deuda con la Antigüedad también en este fenómeno concreto; ni hay tampoco que olvidar que el propio desgaste de los temas míticos, a fuerza de su reiterado uso, es un móvil para esta subversión y este nuevo modo de abordar la tradición legendaria antigua, y que el cambio ideológico que conlleva el Barroco, con su carga de ideales rotos, favorece tal nuevo rumbo ${ }^{24}$. En cualquier caso, Góngora, con su Fábula de Polifemo, con sus romances sobre Hero y Leandro y con su Tisbe, se erige en maestro y modelo de tratamientos narrativos del mito clásico: bien entendiendo el argumento dado por las fuentes como mero pretexto y armazón para la filigrana elocutiva, bien abordándolo desde la óptica burlesca y satírica, bien, en tercer lugar, conjugando ambos modos de acercamiento. La agudeza, la ponderación de contrastes conceptuales y los rasgos

22 Ha estudiado con detenimiento el tema Jesús Ponce Cárdenas en la primera parte de su tesis doctoral. Allí se examinan varios aspectos genológicos importantes: “La mitología bajo el prisma del humor: indagación sobre algunos precedentes clásicos", "Una década para un género: el epilio burlesco entre 1618 y 1628", "Entre los bastidores del mito: Anastasio Pantaleón de Ribera y la tradición literaria", "El aparato narrativo: la configuración retórica del discurso", "El mito como ludus procaz: notas sobre el conceptismo erótico", "Dos lugares comunes del nuevo género: la auctoritas desautorizada y el epitafio burlesco". Remito así a su trabajo: Estudio y edición de las fábulas mitológicas burlescas, sonetos y madrigales de Anastasio Pantaleón de Ribera, Madrid, Universidad Complutense, 2002, pp. 129-287. El mismo investigador también ha desarrollado un interesante estudio de la sexualidad escabrosa entre los ingenios menores del XVII: "De burlas y enfermedades barrocas: la sífilis en la obra poética de Anastasio Pantaleón de Ribera y Miguel Colodrero de Villalobos", Criticón, 100 (2007), pp. 115-142. Por otra parte, una recopilación de epilios jocosos ofrece el libro de Elena Cano, Aunque entiendo poco griego... Fábulas mitológicas burlescas del siglo de oro, Córdoba, Berenice, 2007.

23 Lo mostró hace años en un lúcido artículo Thomas Keeble, “Los orígenes de la parodia de temas mitológicos en la poesía española", Estudios Clásicos 13 (1969) 83-96.

24 Cf. en este sentido también las explicaciones de E. Cano, op. cit., pp. 20 y ss. 
de ingenio son recurso del que hacen pródigo uso algunos de los poetas del género para construir sus relatos míticos en verso, y en ello destaca la pluma de Quevedo, especialmente en sus versiones, también degradatorias, del mito de Hero y Leandro. Por los derroteros de Góngora, con más o menos freno o desenfreno, irán el propio Lope, Jáuregui, Bermúdez y Alfaro, Salcedo Coronel, Villamediana, Colodrero de Villalobos, Castillo Solórzano, Pantaleón de Ribera, Bocángel, Barrionuevo y Peralta, Miguel de Barrios, Polo de Medina y muchos otros. Entre todos ellos, por la calidad de su obra, prodigio de la nueva orientación y de un conocimiento amplio y profundo de las fuentes y de la dicción latina, quiero resaltar la figura de don Juan de Tassis y Peralta, conde de Villamediana (autor de varias fábulas mitológicas: sobre Faetón, Europa, Apolo y Dafne, y el ave Fénix), poeta que ha sido objeto en los últimos tiempos de varias ediciones, ninguna de las cuales -me parece- está a la altura de su obra ni en sintonía con su dominio de la cultura clásica, en especial de la literatura y de la lengua latina; en ello me detendré más adelante.

$\mathrm{Y}$ viene, por fin, una tercera etapa para el género, etapa de declive y disolución que se alarga por todo el siglo XVIII y que se bifurca en dos tendencias, una que es prolongación de la moda culterano-barroca, con su doble posibilidad de sesgo serio o burlesco, y otra que es reacción neoclásica frente a los excesos de la moda barroca y vuelta a una sobriedad renacentista en el tratamiento de la materia mitológica. El conde de Torrepalma, García de la Huerta, Benegassi y Luján, Nieto de Molina, el duque de Medinasidonia y el propio preceptista poético Luján son algunos de los representantes del género en este su último período.

\section{LOS ESTUDIOS SOBRE EL GÉNERO}

El mérito de la ingente obra de Cossío merece siempre el agradecido reconocimiento de los investigadores. La inmensa tarea de inuentio y escrutinio que él realizó es hoy difícilmente imaginable como labor para una sola persona. Se contiene, en efecto, en esas más de novecientas páginas, un catálogo que comprende varias centenas de fábulas mitológicas. Las diversas muestras están ahí situadas en las correspondientes coordenadas de la historia literaria y además analizadas en lo que a sus dependencias y logros estéticos se refiere. Y siempre en una prosa de agradable y amena lectura. Sus criterios han podido ser perfilados y mejorados con los avances de la investigación y de la crítica, y su catálogo de muestras ha podido ampliarse gracias a los nuevos descubrimientos. Pero su obra sigue siendo punto de partida y fundamento para todo estudio del género. Él es el gigante sobre cuyos hombros han de cabalgar necesariamente todos los que de nuevo quieran seguir la huella de la fábula mitológica hispana. Al libro lo enriquecen sobremanera, y aumentan su utilidad, no 
sólo su índice de autores, sino, más aún, su índice de temas; y es particularmente adecuada al contenido esa "breve ilustración pictórica de las fábulas estudiadas" 25 , que ha sido trasladada como tal a la reciente edición ${ }^{26}$ y reproducida en ella a todo color, aunque el número e identidad de las ilustraciones varía notablemente en ambas ediciones. En su introducción, Cossío lleva a cabo un análisis del género en el que puntualiza con acierto cómo las causas del desdén de la crítica hacia este tipo de obras han sido no sólo su consideración como ajenas al genio literario español, sino también lo trabajoso y arduo de su lectura y comprensión; y deja bien claro cómo el interés de su libro se cifra en mostrar una faceta de la cultura y literatura española poco alumbrada antes y tradicionalmente preterida, cuando no oscurecida: la faceta antirrealista, anticastiza y al mismo tiempo universal, clásica e idealista, la que no sólo caracteriza y define parcialmente a la literatura española, sino que la vincula y asocia con el resto de las literaturas europeas. Cossío oscila en su definición del lazo que une a todas las obras que él estudia: comienza por hablar de "provincia de nuestra geografía literaria" y "zona de nuestra poesía", para concluir usando el término de "género", aunque no parece dar relieve especial ni valor estrictamente técnico al vocablo. Sin embargo, ya hemos mostrado arriba su inequívoca continuidad, como tal género, con la tradición alejandrino-neotérica, y hemos explicado que, a nuestro juicio, se trata de un verdadero género épico menor, opuesto tanto a la epopeya como a la lírica, a pesar de sus conexiones, también evidentes, con esos otros dos géneros. Por lo que a sus vínculos con la lírica se refiere, Cossío los ha subrayado hasta el punto de admitir una posible inclusión de las fábulas mitológicas en el género lírico ${ }^{27}$; y un ejemplo de proximidad es la tópicamente inicial descriptio puellae, deudora de la tradición petrarquista. La relación y deuda con la epopeya se desprende de la reiterada presencia en las fábulas de ciertos tópicos cuyo modelo por antonomasia es la Eneida y demás obras de la épica mayor, como la inicial declaración de canto e invocación a la musa, o la écfrasis de lugar que suele encabezar la narración propiamente dicha. Señala también Cossío, y no le falta razón en ello, el predominio de la pretensión retórica y estilística en todas las obras pertinentes a este género; en ese rasgo, además, siguen mostrando su continuidad con los epilios antiguos, que, oponiéndose a la gran epopeya, tenían como meta, reduciendo sus dimensiones, la de alcanzar como libros una mayor perfección estilística, prestando una mayor atención que las epopeyas a la elocutio y a la dispositio. En suma, como los poetas del 27 pusieron de moda a Góngora y lo revalorizaron y sacaron del lóbrego sótano del abandono, así debemos a Cossío,

25 Pp. 851-876 de la edición de Madrid, Espasa-Calpe, 1952.

26 Pp. 431-456, vol. II, Madrid, Istmo, 1999.

27 Cf. op. cit., vol. I, Madrid, ed. Istmo, 1999, p. 20 (= Madrid, ed. Espasa-Calpe, 1952, p. 3): “no será descaminado incluirles en un género lírico al que, por muchas razones que atañen a nuestra sensibilidad, se inclina su evidente carácter híbrido". 
fundamentalmente, este nuevo alumbramiento y reconsideración del género de la fábula mitológica, precisamente aquel en el que Góngora había sido ilustre modelo. La crítica romántica había arremetido contra todo lo que llevaba el señuelo de lo clásico, muy especialmente contra la mitología poética en general y las fábulas mitológicas en particular, y, a pesar de la briosa defensa de un crítico como Alberto Lista ${ }^{28}$, el género dejó de cultivarse y sufrió durante más de un siglo el rechazo de la crítica.

Después de la obra de Cossío, un grupo de trabajos que, a mi juicio, ha tenido un gran interés para el estudio del género es aquel en el que se toma como objeto de análisis una figura o tema mítico determinado, de modo que, arrancando de las fuentes antiguas, se pasa revista a las muestras de diverso género que hay sobre ese tema en la literatura española, poniendo de relieve no sólo las coincidencias, sino también lo particular de cada caso, lo que es dependiente de las modas literarias, o de una especial orientación del autor, o del género elegido; de ese modo se ve perspicuamente cómo la misma materia ha dado ocasión a tratamientos diferentes; se aísla así, con especial nitidez, lo que es común y lo que es distintivo en cada obra, lo uno y lo diverso, esas dos búsquedas propias de la literatura comparada. Hay estudios de este tipo, como el de Stanford sobre Ulises ${ }^{29}$, o el de Galinsky sobre Hércules ${ }^{30}$, que, refiriéndose a la literatura universal, tratan algunas muestras de nuestra literatura, por lo general sólo las de mayor relieve. Pero hay otros que se circunscriben a la literatura española, como el de Pablo Cabañas sobre Orfeo ${ }^{31}$ y el de Antonio Gallego Morell sobre Faetón ${ }^{32}$. La obra de Cabañas, organizada no de modo diacrónico, sino atendiendo a los diferentes motivos que conforman el mito órfico, pierde utilidad; haría falta, al menos -como en el libro de Gallego Morell sobre Faetón- un capítulo inicial que diera cuenta de las obras más representativas siguiendo el orden cronológico. En este sentido el libro de Turner sobre Ícaro (en la poesía española del Renacimiento) me parece ejemplar ${ }^{33}$. Magnífico, como todos sus escritos, es el estudio de María Rosa Lida sobre Dido en España, aunque tampoco se organiza con criterio cronológico ${ }^{34}$. En fin, son muchos los estudios de mitología literaria que, publicados en el último tercio del siglo $\mathrm{XX}$, siguen esta dirección ${ }^{35}$. El auge actual en España de los estudios sobre la tradición clásica

28 En su breve ensayo "Del uso de las fábulas mitológicas", en Artículos críticos y literarios, t. I, La Palma 1840, pp. 164-168.

29 W. Standford, The Ulysses Theme. A study in the adaptability of a traditional Hero, Oxford 1954.

30 G. K. Galinsky, The Herakles Theme, Oxford 1972.

31 P. Cabañas, El mito de Orfeo en la literatura española, Madrid 1948.

32 A. Gallego Morell, El mito de Faetón en la literatura española, Madrid 1961.

33 J. H. Turner, The Myth of Icarus in Spain Renaissance Poetry, Londres 1976.

34 María Rosa Lida de Malkiel, Dido en la literatura española. Su retrato y defensa, Londres 1974.

35 Así los de F. Moya del Baño, M. D. Castro Jiménez, J. Cebrián, V. Cristóbal, A. Rueda, Y. Ruiz Esteban, etc. Remito a mi artículo "Mitología clásica en la literatura española: consideraciones generales y 
conlleva un afán de alumbrar todo lo que es en nuestra literatura herencia grecolatina -tarea acometida sobre todo por los filólogos clásicos- y de ello se beneficia un género de raíces tan helénicas y romanas como el de la fábula mitológica. Del mismo modo, el interés suscitado hacia Góngora después de la generación del 27 no sólo no ha decaído, sino que se ha extendido a todo el movimiento culterano barroco, a su poética y a los numerosos autores que la representan, de lo cual se deriva igualmente una mirada incisiva, por parte de los hispanistas, hacia la poesía narrativa de tema mitológico ${ }^{36}$.

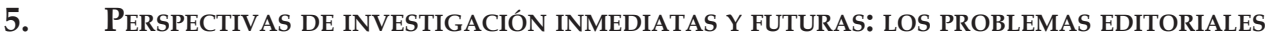

En qué líneas se puede y se debe seguir trabajando sobre la fábula mitológica? Yo diría que, al menos, en el ámbito de la correcta edición y de la correcta anotación, como tarea primera y previa a todo ulterior estudio. Para ello, creo que es necesario al editor y al comentarista un buen dominio de la mitología y del latín: para estar a la altura de la formación de los autores de esos textos poéticos, entender así sus referencias -a veces muy abstrusas, superfluo es decirlo- y elegir de entre las diferentes opciones brindadas por la tradición textual aquella que mejor se avenga con el clasicismo de sus autores, aquella que ofrezca coherencia mitográfica o que esté avalada por las fuentes literarias en que se haya basado el autor, aquella que, por más que difícil, sea susceptible de explicarse como latinismo sintáctico, semántico o prosódico. En este ámbito los esfuerzos aunados de hispanistas y clasicistas pueden dar buenos frutos.

De la problemática editorial y de anotación, a veces mal resuelta, daré a continuación algunos ejemplos, sacado el primero del Orfeo de Jáuregui, pero todos los demás de la Fábula de Faetón de Villamediana ${ }^{37}$.

bibliografía", Cuadernos de Filología Clásica. Estudios Latinos 18 (2000), pp. 29-76.

36 Cf. sobre todo D. Alonso, Estudios y ensayos gongorinos, Madrid, Gredos, 1955; id., Góngora y el Polifemo, Madrid, Gredos, 1967 ( $5^{a}$ ed., en 3 vols.); una reseña por J. M. Micó de las publicaciones gongorinas desde 1982 a 1990 puede hallarse en F. Rico, Historia y crítica de la literatura española. Siglos de oro: Barroco. Primer suplemento, Barcelona, ed. Crítica, 1992, pp. 210-225. Desde un ámbito comparatista, reviste gran importancia el estudio de María Cristina Cabani, El gran ojo de Polifemo. Visión y voyeurismo en la tradición barroca de un mito clásico, Málaga, Universidad de Málaga, 2007. También pueden verse ahora dos nuevas monografías de Jesús Ponce Cárdenas: Cinco ensayos polifémicos, Málaga, Universidad de Málaga, 2009 y El tapiz narrativo del Polifemo: eros y elipsis, Barcelona, Universitat Pompeu-Fabra, 2010. Al mismo investigador complutense se debe la más reciente edición de la obra magna gongorina: Fábula de Polifemo y Galatea, Madrid, Cátedra, 2010. Para comprender el contexto de producción del epilio barroco, puede resultar asimismo interesante la lectura de J. Ponce Cárdenas, "Góngora y el conde de Niebla: las sutiles gestiones del mecenazgo", Criticón, 106 (2009), pp. 99-146 (en especial, pp. 129-134). Los datos que allí se ofrecen sobre el escritor cordobés y los miembros de la Casa de Guzmán pueden ampliarse asimismo en un nuevo estudio del investigador complutense: "Formas breves y géneros epidícticos entre Tasso y Góngora. El ciclo a los marqueses de Ayamonte", Romanische Forschungen, 122 (2010), pp. 183-219.

37 Ya ofrecí -y creo que resolví- un primer ejemplo de esta problemática, mal resuelta en todas las ediciones, a propósito de la octava penúltima del Faetón, en Cuadernos de Filología Clásica. Estudios Latinos 17 (1999), pp. 253-258. 
a) De la importancia del latinismo (léxico-semántico, sintáctico, etc.) en la fábula mitológica, y de la necesidad de su correspondiente glosa, puede dar por doquier buen ejemplo el Orfeo de Juan de Jáuregui de modo que está precisado, no menos que el Polifemo o que las fábulas de Villamediana, como decíamos, de una traducción a la lengua de uso cotidiano (explica ='desdobla', 'desenvuelve'; opugnar = 'conquistar'; curso $=$ 'carrera'; agravia $=$ 'ejerce peso sobre algo'; ponderación $=$ 'peso'; rubrica $=$ 'enrojece', etc.) Pero esto llega a extremos anecdóticos. Sépase que en la edición de Pablo Cabañas ${ }^{38}$, que es reproducción fiel de la primera edición de 1624, se contiene una breve tabla final que reza "Erratas de la edición príncipe, corregidas en esta edición", donde se dan cinco correcciones, las últimas de las cuales son: en p. 64, lín. 1: pacíficas> pacíficos, y p. 79, lín. 21: Baccantes> Bacantes. Pues bien, esas dos correcciones, son ultracorrecciones equivocadas, porque la secuencia "A pacíficas tigres y leones" es perfectamente latinizante, ya que en el texto latino de Virgilio (Aen. IV 367: Caucasus Hyrcanaeque admorunt ubera tigres) se habla de tigres femeninos (tigresas), y en el propio Jáuregui se repite este género para tigre en p. 76, canto V ("menos se abstiene que la tigre o lobo"), y la doble c de Baccantes es simple grafía latinizante (Bacchantes).

b) Entrando a considerar la Fábula de Faetón de Villamediana, en primer lugar me quiero detener en un asunto de prosodia. El famoso río asiático que confluye con el Tigris y bordea la tierra de Mesopotamia recibe en griego el nombre de Euphrátes y ese mismo nombre, transcrito, es el que se le da en latín, con una a larga en la sílaba penúltima, de modo que es una palabra llana. Actualmente en castellano, por no importa qué razones, ese nombre se pronuncia y se escribe generalmente como palabra esdrújula (aunque Ruiz de Elvira, siempre tan atento a estas cuestiones, sigue en sus trabajos acentuando como llana la palabra y aunque Fernández-Galiano defiende también como correcta la forma llana ${ }^{39}$ ), con una transcripción incorrecta, pero ya totalmente divulgada y muy difícil de erradicar. Sin embargo, en el castellano del Siglo de Oro esta palabra había sido transcrita correctamente, con acento en la penúltima y no en la antepenúltima, como se ve en muchos testimonios: por ejemplo, en este soneto burlesco de Pedro Espinosa, primer cuarteto:

Cantar que nacen perlas y granates si estampas los toribios de tus patas, llamar coturnos breves tus zapatas, escrebir que eres ninfa del Eufrates...,

o en este otro de Fernando de Herrera ("Alégrate, Danubio ympetuoso”), primer terceto:

38 Madrid, C.S.I.C., 1948.

39 La transcripción castellana de los nombres propios griegos, Madrid, Gredos, 1969, p. 95. 
Veréys el fiero y áspero tirano

dexar del largo Eufrates esta parte

por fuerça y sangre y hierro y fuego y muerte;

o en este pasaje de El nuevo mundo descubierto por Cristóbal Colón de Lope de Vega, jornada I, vv. 396-399:

(Oh ambición, qué no habrá que no retrates!

Ved lo que tiene aqueste loco impreso;

el Indo, el Nilo, el Ganges y el Eufrates

medirá con un átomo,

o en este otro de La hija del aire (segunda parte), de Calderón, jornada III, vv. 678681:

\author{
Que hoy prevenido a bélicos combates \\ sobre el rápido curso del Eufrates, \\ libertad le he de dar y desengaños \\ de que hay mucho valor en pocos años.
}

Si eso es así, entonces el verso 1289 de la Fábula de Faetón, en el que aparece dicho nombre propio (verso que deriva claramente de Ovidio, Met. II 248: Arsit et Euphrates Babylonius, arsit Orontes), está bien editado -con esa palabra sin la tilde acentual- sólo en la edición de J. M. Rozas ${ }^{40}$ : "Eufrates en Armenia, en Siria Oronte"; pero no en las más modernas ${ }^{41}$ de J. F. Ruiz Casanova ${ }^{42}$, de María Teresa Ruestes ${ }^{43}$ y de Lidia Gutiérrez Arranz ${ }^{44}$, que no han tenido en cuenta la prosodia latinizante de esta palabra en el Siglo de Oro y la han acentuado tal y como hoy se acentúa: como esdrújula. Es verdad que esto son minucias. Pero esas minucias son la parte fundamental y previa de la tarea de los filólogos, a quienes, como lema, nos cuadra muy bien la sentencia virgiliana In tenui labor de Georg. IV 6.

c) Y siguiendo con las minucias, vayamos ya a cuestiones de puntos y comas, cuya colocación es indicativa de cómo ha entendido el texto el editor y cómo se lo

40 Villamediana, Obras, Madrid, ed. Clásicos Castalia, 1980, p. 249.

41 No incluyo dentro de éstas la de F. Pedraza, Conde de Villamediana, Obras, Aranjuez, Ara Iovis, 1986, por ser facsímil de la edición príncipe.

42 Conde de Villamediana, Poesía impresa completa, Madrid, Cátedra, 1990, p. 590.

43 Conde de Villamediana, Poesía, Barcelona, Planeta, 1992, p. 283; aquí consta como verso 1337.

44 Conde de Villamediana, Las fábulas mitológicas, Kassel, Reichenberger, 1999, p. 257. Esta edición se atreve, tratando de llenar el hueco de las tres anteriores, a comentar el texto con mayor detenimiento; pero es de lamentar que una obra tan voluminosa, con un análisis tan pormenorizado de los distintos manuscritos, con un aparato textual tan detallado, y con el anexo, tan de agradecer por otra parte, de la traducción latina del Faetón por Vicente Mariner, esté tan salpicada de equivocaciones y desaciertos. Ya así lo advertía en buena parte la reseña de Jesús Ponce Cárdenas en Revista de Literatura 62, 124 (2000), pp. 617-619. En cambio, la recensión de M. Nasif -publicada en Incipit, 19 (1999), pp. 356-358- se quedaba en la cáscara, sin entrar en el aspecto verdaderamente editorial y exegético de la obra. 
propone entender al lector. De la estrofa 67 de la misma Fábula de Faetón, leemos así los cuatro últimos versos de las cuatro citadas ediciones modernas:

$$
\begin{aligned}
& \text {... entre cuyas centellas carmesíes, } \\
& \text { no perdonada del arpón ardiente, } \\
& \text { del hijo bella madre en perlas lava } \\
& \text { mal herida beldad de deidad brava. }
\end{aligned}
$$

Versos son éstos que se refieren obviamente a Venus, que llora enamorada sobre Adonis sangrante (=centellas carmesíes) y moribundo y deja caer sus lágrimas (=en perlas lava) en el cuerpo hermoso (= beldad) del mancebo, herido por el colmillo del jabalí enviado por Marte o resultado de la metamorfosis del propio Marte (= deidad brava). Es la diosa, pues, una madre bella, herida por la flecha o arpón de su propio hijo Cupido, dios del amor, que ni siquiera en su misión flechadora de dioses y hombres se ha detenido ante su madre, ni siquiera a ella ha perdonado: por eso es obvio que el determinante "del hijo" lo es de "arpón ardiente", y la secuencia "del arpón ardiente del hijo" funciona como agente del participio pasivo "perdonada", siendo todo ello ("no perdonada del arpón ardiente del hijo") una explicación de "bella madre" que debe aislarse entre comas. Por lo tanto, la coma no debe ir al fin del verso 534 (ó 550 en la ed. de Ruestes), sino detrás de "del hijo", en el verso siguiente. En su yerro compartido, las cuatro ediciones modernas proclaman con su puntuación, por una parte, la necia tautología de que una madre es madre de su hijo, y, por otra, que el "arpón ardiente" que ha herido a esa madre puede ser el arpón de cualquiera.

d) Prosiguiendo con cuestión de comas, vayamos a los cuatro primeros versos de la estrofa 63 del mismo poema (=64 en la ed. de Ruestes), que, según nuestra propuesta, deben leerse tal y como los ofrece Ruestes, así puntuados:

\footnotetext{
El gran pastor que vio desnuda en Ida

de tres deidades competida gloria

a Venus áurea prenda dio, vencida

de su cabello, en premio de victoria...
}

Se trata obviamente de Paris, que en el monte Ida contempló la desnudez de Juno, Minerva y Venus, diosas que se mostraban ante él sin vestiduras compitiendo por ver cuál era juzgada la más bella y recibía la gloria del premio; la victoria -como es sabido- la obtuvo Venus, que recibió por ello la manzana de oro -pero el cabello de Venus era aún más dorado que la manzana- de manos de Paris. En consecuencia es ilógico separar con comas el sujeto del predicado -como hacen las otras tres ediciones, situando una coma al fin del verso segundo-, e ilógico separar con coma el verbo de su complemento directo -como hace una de ellas, poniendo coma al fin del primer verso. 
e) Otro ejemplo más de puntuación equivocada es el que tenemos en la estrofa 168 del mismo poema (=174 Ruestes), estrofa en la que, en el primer verso, hay aún otro problema textual de mayor envergadura en el que también nos detendremos. El texto está así editado por Rozas:

Palemón, Melicerta, Panopea,
deidades de las ondas cristalinas,
moviendo están contra la luz febea
fuerza inútil de escamas y de espinas.
Tu justicia clamando en vano Astrea
en ya seca región voces nerinas,
que no extingue la sed del gran portento
cuanto contiene el mar salado argento.

La estrofa hay que entenderla como una amplificatio del testimonio ovidiano sobre los desastres ocasionados por Faetón al asumir la tarea de guiar el carro del Sol, su padre. Ovidio decía, a propósito de los efectos sobre el mar, que éste se había encogido y que era ya un llano de arena seca lo que poco antes era el ponto; dice también que, al evaporarse el agua, emergieron montes antes submarinos y que así se originaron nuevas islas en el archipiélago de las Cícladas (et mare contrahitur, siccaeque est campus harenae,/ quod modo pontus erat, quosque altum texerat aequor,/ exsistunt montes et sparsas Cycladas augent: Met. II 262-264); más adelante, respecto a los dioses del mar cuenta cómo era fama que Nereo y Doris, y las hijas de ambos, las Nereidas, se escondieron en grutas a las que incluso llegaba algo de calor, y que el propio Neptuno sacó del agua sus brazos y cabeza y tuvo que sumergirse de nuevo al sentir el aire abrasador (ipsum quoque Nerea fama est/ Doridaque et natas tepidis latuisse sub antris;/ ter Neptunus aquis cum toruo bracchia uultu/ exserere ausus erat, ter non tulit aëris ignes: Met. II 268-271). Aquí, sin embargo, Villamediana, aunque se hace eco en las octavas 166 y 167 del testimonio ovidiano, amplifica hablando de otros dioses marinos de los que nada decía el poeta de las Metamorfosis: se trata, en primer lugar, de Palemon, dios marino que es el resultado de la apoteosis de Melicertes, hijo de Ino y Atamante ${ }^{45}$; su nombre debe ser transcrito en castellano como palabra llana, habida cuenta de que en latín ese nombre tiene diptongo -ae en la sílaba penúltima y, al ser larga, es -según la regla latina de acentuación- la que debe llevar y lleva el acento: de manera que, calcando en castellano dicha prosodia ${ }^{46}$, el resultado ha de ser "Palemon" y no "Palemón" (aunque la analogía con nombres como Cicerón, Salomón, Acteón o Filemón actúe como fuerza en sentido contrario). Es verosímil que así fuera también la prosodia del nombre en los siglos XVI y XVII

45 Sobre su completa leyenda véase A. Ruiz de Elvira, Mitología Clásica, Madrid, ed. Gredos, 1975, pp. 180-181.

46 Así, como Palemon, figura el nombre del dios en el ya citado manual de Ruiz de Elvira, pp. 108, 181, 451 y 527. Sobre tal aspecto cf. el clásico y ya citado libro de M. Fernandez-Galiano, La transcripción castellana de los nombres propios griegos, aunque precisamente a propósito de este nombre se da aquí (p. 29, punto 34), incongruentemente, a mi juicio, la transcripción del mismo como palabra aguda. 
-nombre y personaje, por lo demás, de muy escasa frecuencia y relevancia-, aunque su posición en el verso que comentamos casi nada nos aclara al respecto; no obstante, habida cuenta de la tendencia en el endecasílabo al ritmo yámbico, con acentos en la segunda, cuarta y especialmente en la sexta, yo creo que es bastante probable en este nombre propio una acentuación como palabra llana y no como aguda. A continuación tenemos otro nombre propio en el verso: Melicerta, que lo es, a pesar de su terminación en - $a$, del mancebo transformado luego en dios con el nombre de Palemon. Tenemos, pues, una no leve dificultad, que no me atrevo aún a resolver y en la que dudan los editores: porque los dos nombres corresponden a distintas fases -mortal y divina- del mismo personaje. Una solución bastante plausible es la que da Gutiérrez Arranz, que probablemente acierta aquí, frente a las tres ediciones anteriores, eliminando la coma entre ambos vocablos por entender que se trata del mismo personaje, aludido aquí con sus dos nombres seguidos, como si el segundo fuera apelativo del primero (por cierto que la traducción latina de ese pasaje por Vicente Mariner entiende el verso de modo similar al unir los dos nombres del dios con la conjunción copulativa atque que significa propiamente 'y además', 'e incluso': formosa et Panope, Melicertes atque Palaemon). Sin embargo, para lo que no veo apoyo suficiente es para corregir-como hace la misma editora y comentarista- toda la tradición impresa, áurea y contemporánea, que da, para la segunda parte del verso, la secuencia Melicerta, Panopea. Melicerta no está propiamente en la tradición manuscrita; en su lugar aparece Menicertas en uno de los testimonios (Ms. 3959 BN) y Doris, Glauco en otro (Britto); la tradición impresa antes de 1999 es Melicerta (frente a Menicertas, que da un manuscrito, y frente a Melicertes, que edita Gutiérrez Arranz) y tiene el apoyo de las fuentes: pues en latín este nombre, a pesar de ser masculino, se declina por la primera, como puede comprobarse en este verso virgiliano: Glauco et Panopeae et Inoo Melicertae (Georg. I 437), verso que, por cierto, estaba latente sin duda en la memoria de Villamediana cuando escribió el nombre de Melicertes (Melicerta) asociado al de Panopea, una nereida. De modo que Melicerta, de la tradición textual impresa, tiene todos los visos de ser la lectura correcta, y parecen acertados así los otros tres editores al mantenerla. Por tanto, este primer verso, de momento (pues para pronunciarme definitivamente tendría que considerar con más tiempo la lectura Doris, Glauco del manuscrito de Méndez de Britto), yo lo leería así: "Palemon Melicerta, Panopea". Y vayamos a los versos cuarto y quinto de la octava. Todas las ediciones dan puntuación fuerte entre ambos versos, dejando sin oración principal la secuencia formada por los cuatro últimos versos. Es obvio que todas yerran, porque la oración de gerundio clamando... voces nerinas ha de ser necesariamente dependiente de la oración constituida por los cuatro primeros versos, y por tanto es incorrecto separarla de aquélla por una punto. Pero además, todas yerran también al leer el verso quinto de esta estrofa puntuando de este modo (con la variante aclamando en vez de clamando de Gutiérrez Arranz): “Tu justicia clamando en vano Astrea". ¿Por 
qué se equivocan? Porque al puntuar así entienden -me parece- que Astrea sea el sujeto de clamando (aunque en ese caso no sé cómo se decidirían en la alternativa de elegir como objeto directo tu justicia o voces nerinas): lo cual lleva al absurdo. Astrea es un vocativo, por lo cual debe ir entre comas; a él obviamente se refiere tu justicia, pues sabido es que a la diosa Justicia se la llama también Astrea, ya que, a fines de la edad de oro, se marchó de la tierra y emigró al cielo situándose entre los astros como una constelación, la de Virgo ${ }^{47}$; las voces nerinas son aquí las voces de los dioses del mar, en general, o bien de las nereidas en particular. De modo que toda la octava debería ser, a mi juicio, y con las reservas antes expresadas a propósito del primer verso, editada así:

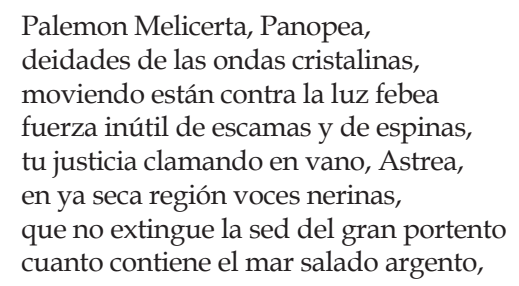

texto este del que se alejan, por una u otra razón, todas las modernas ediciones: por descuido de la prosodia latinizante, por no reparar en las fuentes latinas (el citado verso de las Geórgicas) y por un demasiado apego a la tradición textual previa sin cuestionar su viabilidad ni temática ni sintáctica.

f) $Y$ ese desconcierto aumenta cuando se trata de anotar correctamente los debatidos versos. Así, a propósito de Panopea, uno de los editores anota explicando: "Panopeo [sic]. Hijo de Foco y Asteria. Fue uno de los constructores del caballo de Troya”. El lector de esta nota quedará razonablemente estupefacto al ver que en el texto se dice Panopea y en la nota se cambia el sexo del personaje, estupefacto también al comprobar que -según el comentarista- el poeta llama "deidad de las ondas cristalinas" a un varón constructor del caballo de Troya, al que se asocia, con toda naturalidad, a Palemon-Melicertes; y no sabrá de qué manera ni por qué razón ese constructor del caballo, nuevo y sorprendente dios marino, se indigna contra el destructivo Faetón que, por si fuera poco, debe situarse cronológicamente por los menos cinco siglos antes de la guerra de Troya, allá por los siglos XVIII ó XIX antes de Cristo ${ }^{48}$. A propósito de la misma palabra, otro de los comentaristas, por su parte, pone una nota que explica, también sorprendentemente, de este modo: "Panopea: Ciudad de donde es originario el héroe Panopeo. Aquí, por razón de la rima, utilizado en vez de Panopeo". A continuación el lector de esa nota se preguntará sin duda, no menos extrañado que antes, qué hace

47 Cf. A. Ruiz de Elvira, op. cit., pp. 67-68 y 115.

48 Sobre cronología mítica véase A. Ruiz de Elvira, op. cit., pp. 23-26 y 120-122. 
una ciudad entre los dioses marinos y por qué el propio poeta dice de esa ciudad que es -junto con Palemon Melicertes- una deidad de las ondas cristalinas ${ }^{49}$.

g) Es difícil, sí, anotar adecuadamente una poesía tan trufada de erudición y doctrina. Para entender, en efecto, la poesía cultista del Barroco hay que estar a la misma altura cultural que los 'culteranos': hay que conocer al dedillo la mitología en sus fuentes primarias y hay que saber tanto latín como aquellos poetas sabían. Una poesía que complica tanto la expresión con metáforas y perífrasis continuas y continuos calcos semánticos, léxicos y prosódicos de la lengua madre necesita, en primer lugar, ser traducida al lenguaje cotidiano, o poco menos. Ahí están las ejemplares prosificaciones y glosas de Dámaso Alonso. Esa misma “traducción” es requerida también, sin lugar a dudas, por las fábulas de Villamediana. A los anotadores se les presenta el reto de explicar no solamente tal o cual término o expresión -como muchos hacen para salir del paso y muchas veces mal-, sino la de aclarar con palabras más inteligibles que las del poeta el quid de todo el texto, su mensaje. Hemos visto antes algunos palmarios errores de comentaristas de Villamediana. Y vamos a seguir viendo ejemplos de mala anotación e incomprensión del mensaje poético, sobre todo por confusiones en el ámbito de la mitología, pero también por ofrecer, superfluamente, una información complementaria totalmente ociosa e inoportuna, que deja el texto sin aclarar. Lo diré una vez más: a la hora de enfrentarnos al estudio de las fábulas mitológicas españolas hay un reto permanente, previo a todos los demás: el de entender y hacer entender el contenido, el de desentrañar el significado latente bajo tan complejos y tortuosos significantes.

Con respecto a las notas de alguno de los comentaristas de Villamediana advertiré cómo en ellas es inadecuada la referencia a los personajes con su nombre griego; los nombres griegos de los dioses no tienen ningún sentido para la poesía del XVII, que conoce la mitología a través de las fuentes latinas: será, por tanto, siempre Júpiter y nunca Zeus; siempre Diana y nunca Ártemis; y siempre Mercurio y nunca Hermes.

49 Me atrevo a conjeturar que lo que ha llevado al comentarista a anotar de ese modo ha sido la consulta al diccionario de Grimal (Diccionario de Mitología griega y romana, Barcelona, ed. Paidos, 1982), donde no aparece la voz "Panopea", pero sí "Panopeo", y en esta última voz, como primera información, se lee: "Panopeo es el héroe epónimo de la ciudad de igual nombre...". Panopea es el nombre de una nereida, como ya hemos dicho, y por su singularidad y escasa entidad mitográfica no aparece en esta obra consignado autónomamente como voz, pero sí aparece bajo la voz "Nereidas", al lado de otros setenta y seis nombres de hijas de Nereo y Doris. Las fuentes antiguas para los nombres de estas diosas marinas son: Hesíodo en la Teogonía (243-262), que da 51 nombres; Homero en la Ilíada (XVIII 34-49), que da 33 nombres; Apolodoro en su Biblioteca (I 2, 7), que da 45 nombres; e Higino en sus Fábulas (praef. 8), que da 49 nombres. En esas cuatro listas figura Pánope, la que, según transcripción virgiliana, consta como Panopea y como tal también en el verso de Villamediana. Para más información mitográfica sobre las Nereidas véase A. Ruiz de Elvira, op. cit., p. 41. 
Una errada explicación, otra más de las muchas, se halla en las notas a la estrofa 21 del Faetón de una de las ediciones. La primera mitad de la octava dice así:

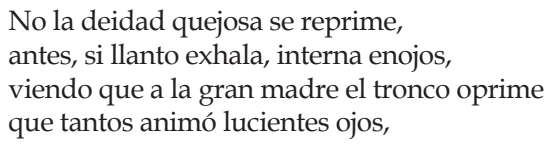

versos en los que el poeta significa el dolor de Juno al ver que el tronco decapitado de Argos, el de los cien ojos, yace sobre la tierra, la gran madre universal. Pero quien anota sostiene que esa gran madre es Ío, y no entiende qué es eso de oprimir a la gran madre, de modo que explica: "vv. 163-164: Yace Argos, guardián de la gran madre -la vaca Ío del vs. 163-, muerto a manos de Hermes..."

En la octava 27, también sus primeros cuatro versos están deficientemente anotados en las ediciones: porque tres de ellas nada explican sobre el contenido preciso (tal vez porque sus autores creen que son versos completamente claros o porque siguen su tónica de ser parcos en la anotación), y la que sí lo hace, se equivoca. El texto poético es el siguiente:

Ésta fue diosa y della tuvo el mundo al gran hijo, más claro que su abuelo, gloriosa producción, semen fecundo, rayo feliz de lo mejor del cielo.

En efecto, Ío fue, tras haber sido amada por Júpiter, madre de Épafo, que llegó a ser más esclarecido que su abuelo Ínaco, río padre de Ío: él, como hijo de Júpiter, puede llamarse "rayo feliz de lo mejor del cielo". Pero el único conato de ilustración que hallamos de estos versos dice así: "vv. 209-210: Ío, antes retratada como ninfa, ahora diosa, engendró a Épafo, hijo de Febo, "más claro", más ilustre, que Zeus..." Aparte del ya censurado empleo del nombre griego para el dios supremo, se acumulan aquí tres deslices: no sólo Épafo no es hijo de Febo, sino que, evidentemente, nunca podría decirse de él que fue más ilustre que Júpiter, el rey de los dioses, que, claro está, no era abuelo suyo, sino su padre.

La segunda parte de la estrofa 31 de la misma obra contiene las palabras de Épafo dirigidas a Faetón, con la siguiente jactancia:

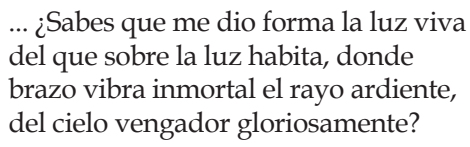

El joven hijo de Júpiter proclama su alta ascendencia: él es hijo de aquel que habita sobre la luz, en lo más alto del cielo, por encima del curso del sol, y desde allí el brazo inmortal de Júpiter dispara el rayo, instrumento aquel que fue castigador en 
otro tiempo de la osadía de los gigantes, que se sublevaron contra el dios soberano, y vengador del cielo, al que aquéllos querían encaramarse. Pues, en efecto, Júpiter usó del rayo por primera vez en la Gigantomaquia (cf. Ovidio, Met. I154-155). De modo que la secuencia "del cielo vengador gloriosamente" determina a "rayo ardiente" casi con toda seguridad, o bien a "brazo... inmortal". Pero estos versos son glosados en una de las ediciones con una inoportuna cita de Grimal, que no atiende a esta relación entre el rayo y la venganza y sostiene que "vengador" se refiere a "Zeus", cosa sintácticamente imposible. Y no creo oportuno ya seguir insistiendo.

\section{Conclusiones.}

De todo lo dicho extraigo, para acabar, unas cuantas conclusiones: 1) que el género de la fábula mitológica supone una continuidad con el epilio grecorromano, género épico promovido por alejandrinos y neotéricos; 2) que las Metamorfosis de Ovidio son la fuente argumental más frecuente para este tipo de obras; 3) que el nombre de dicho género implica no sólo la noción de relato, sino también la de una materia que no es ni realista ni histórica; 4) que se ha cultivado en España desde el Renacimiento al Neoclasicismo, con un momento cumbre en el siglo XVII, promovido por la moda cultista; 5) que la obra de Cossío, a pesar de contener ciertas valoraciones que ya no se sostienen y algunas ligerezas, es el hito fundamental de referencia para el estudio del género; 6) que por ser éste un tipo de obras anclado por naturaleza en el ámbito de la tradición clásica se hace precisa para el investigador una profunda formación clasicista, o dicho de otro modo, que es ésta una parcela de los estudios literarios que convoca a la estrecha colaboración de filólogos clásicos e hispánicos; 7) que aún hay mucha labor por delante en este campo: como tarea primera, la confección de buenas ediciones y buenos comentarios, fundados en un conocimiento adecuado de las fuentes mitográficas y de la propia lengua latina. 